\title{
Gastrointestinal Examinations With a 2,048- $\times$ 2,048-Pixel Image Intensifier Television Digital Radiography System
}

\author{
Yuji Baba, Mutsumasa Takahashi, Tadatoshi Tsuchigami, and Yoshiharu Higashida
}

The clinical usefulness of a 2,048- $\times$ 2,048-pixel matrix image intensifier television digital radiography system was evaluated. Screen-film and digital images (with and without postprocessing) of the upper and lower gastrointestinal (GI) tract were used for clinical evaluation. For the upper GI tract, digital images processed with unsharp mask techniques were comparable in quality to screen-film images before and after upgrading the system. For the lower GI tract, screen-film images were better than digital images, except for those processed with a 2,048- $\times 2,048$-line monitor was comparable to a screen-film system.

Copyright 11995 by W.B. Saunders Company

KEY WORDS: digital radiography, image intensifier television digital radiography, gastrointestinal examination, cathode-ray tube diagnosis.

$\mathbf{T}$ HE DIGITAL RADIOGRAPHY system, using an image intensifier television (II TV) system, provided advantages over conventional screen-film radiography in data acquisition, transmission, processing, and instant display. ${ }^{1-3}$ However, critical limitations of II TV digital system include lower spatial resolution and smaller imaging fields. ${ }^{4-6}$ Although several approaches have been attempted to solve these problems, ${ }^{1-4}$ resolution properties of the II TV digital system currently used are still lower compared with conventional screen-film systems, and detection of various subtle abnormalities are limited in clinical examinations.

We have reported on development of a highresolution II TV digital system with a $2,048-x$ 2,048-pixel matrix image intensifier. ${ }^{4,7}$ We have recently upgraded the system with a new TV camera and an $\mathrm{x}$-ray tube with a $0.3-\mathrm{mm}$ focal spot and reported the basic properties and clinical usefulness of the new system for gastrointestinal (GI) examinations before and after upgrading. ${ }^{8-10}$

From the Department of Radiology, Kumamoto University, School of Medicine, Kumamoto, Japan.

Address reprint requests to Yuji Baba, MD, Department of Radiology, Kumamoto University, School of Medicine, Honjo

1-1-1, Kumamoto City, Kumamoto, Japan.

Copyright 101995 by W.B. Saunders Company

0897-1889/95/0801-1017\$3.00/0
In this report, the usefulness of cathode-ray tube (CRT) diagnosis, including multi-image display and the cost of image storage is also discussed.

\section{TV DIGITAL RADIOGRAPHY SYSTEM}

Major components of our new system consisted of a TV camera, a triple-mode (12-, 9-, and 7-in) II, an image processor, two TV monitors, laser printers, and an image file with a large memory capacity. ${ }^{4}$ The analog digital converter has a capability of 10 -bit conversion at a rate of $20 \mathrm{MHz}$. Images can be acquired in the image matrix sizes of $1,024 \times 1,024$ and 2,048 $\times$ 2,048 pixels on each mode of II.

Each acquired image was processed automatically by a number of digital-processing algorithms, including unsharp masking technique, ${ }^{11,12}$ and instantly displayed on TV monitors with $1,024-\times 1,024$ - and 2,048- $\times 2,048$-pixel matrices, followed by transfer to hard copies and digital storage.

The distance between the focal spot and the table top was $100 \mathrm{~cm}$ for fluoroscopic (digital) examinations. The distance between the screenfilm and the table top was $5 \mathrm{~cm}$, whereas the distance between the II and the table top was 15 $\mathrm{cm}$. Conventional screen-film radiography was obtained using medium-speed screen-film system placed in front of the II surface.

\section{COMPARISON OF DIGITAL IMAGES WITH SCREEN-FILM SYSTEM}

One hundred and sixty-nine upper GI studies and 26 lower GI studies were obtained with II TV (1,024-pixel), II TV (2,048-pixel) and screenfilm systems. ${ }^{10}$ For the upper GI studies, the 9-inch mode of II was routinely used, whereas 12-inch mode was applied for imaging of the

Table 1. Radiographic Techniques

\begin{tabular}{lcccccc}
\hline Technique & $\mathrm{kV}$ & $\mathrm{mA}$ & $\mathrm{msec}$ & $\begin{array}{c}\text { SID } \\
(\mathrm{cm})\end{array}$ & $\begin{array}{c}\text { Focus } \\
(\mathrm{mm})\end{array}$ & $\begin{array}{c}\text { Relative } \\
\text { Dose }\end{array}$ \\
\hline II TV & $85-95$ & 100 & $50-60$ & 115 & 0.3 & 0.5 \\
Screen film & $85-95$ & 300 & $60-75$ & 105 & 0.8 & 1.0 \\
\hline
\end{tabular}

Reprinted with permission from Takahashi et al. ${ }^{10}$ 
Table 2. Comparison of Image Quality of II TV Digital Systems With Screen-Film System (upper GI series)

\begin{tabular}{|c|c|c|c|c|c|c|}
\hline \multirow[b]{2}{*}{ Technique } & \multicolumn{5}{|c|}{ Scores } & \multirow[b]{2}{*}{ Average } \\
\hline & 1 & 2 & 3 & 4 & 5 & \\
\hline \multicolumn{7}{|l|}{ II TV $(1,024$ pixels $)$} \\
\hline Original $(n=507)$ & $7(1.4 \%)$ & $287(56.6 \%)$ & $192(37.9 \%)$ & $21(4.1 \%)$ & $0\langle 0 \%\rangle$ & $2.44 \pm 0.60$ \\
\hline Unsharp masking $(n=507)$ & $4(0.8 \%)$ & $80(15.8 \%)$ & $286(56.4 \%)$ & $135(26.6 \%)$ & $2(0.4 \%)$ & $3.09 \pm 0.68$ \\
\hline \multicolumn{7}{|l|}{ II TV $(2,048$ pixels $)$} \\
\hline Original $(n=489$ ) & $1(0.2 \%)$ & $178(36.4 \%)$ & $284(58.1 \%)$ & $26(5.3 \%)$ & $0(0 \%)$ & $2.70 \pm 0.57$ \\
\hline Unsharp masking ( $n=489)$ & $1(0.2 \%)$ & $26(5.3 \%)$ & $254(52.0 \%)$ & $205(41.9 \%)$ & $3(0.6 \%)$ & $3.38 \pm 0.61$ \\
\hline
\end{tabular}

Values are the number of evaluations for each score. Reprinted with permission from Takahashi et al. ${ }^{10}$

lower GI tract. In addition to original images, unsharp masking images were obtained and evaluated. Unsharp masking enhanced the high spatial frequency range $(0.25$ line pairs $/ \mathrm{mm}) 2$ times. Each digital image was transferred to hard copy by a laser printer after image processing. Mask size and weighting factors were subjectively selected by each observer before the observer performance experiment.

The observers subjectively evaluated these radiographic examinations and gave a score to each examination on the basis of the overall diagnostic quality of the images in comparison with the screen-film (1, inferior; 2 , slightly inferior; 3 , equal; 4 , slightly superior; 5 , superior to screen-film images). The scores were averaged for comparison. Radiographic technique are shown in Table 1.

\section{UPPER GI STUDY}

II TV (1,024-pixel) and II TV (2,048-pixel) images with unsharp masking were equal or superior to those obtained with the screen-film system (Table 2$)$. II TV $(2,048-\times 2,048$-pixel) images were significantly superior to II TV $(1,024-\times 1,024$-pixel $)$ images $(P<.01)$.

\section{LOWER GI STUDY}

II TV (2,048-pixel) images with unsharp masking were almost equal to those from the screen- film system. Original II TV (1,024- and 2,048pixel) and II TV (1,024-pixel) images with unsharp masking were inferior to the screenfilm system images (Table 3). II TV (2,048pixel) images were significantly superior to II TV $(1,024-\times 1,024$-pixel) images $(P<.01)$.

\section{CRT DIAGNOSIS}

The usefulness of CRT diagnosis was also evaluated in 26 upper GI studies. Two radiologists have evaluated the diagnostic value of digital images on either 1,024- or 2,048-line CRT in comparison with the screen-film system. The usefulness of a multiple-image display system was also evaluated.

The diagnostic value of screen-film images and 2,048-pixel matrix II TV images on a 2,048-line CRT were almost equivalent to the screen-film system, and image processing such as zooming improved the diagnostic value of II TV images (Table 4). In most cases, diagnosis using a multi-image display system was easy or possible (Table 5).

\section{COMMENTS}

The decisive advantages of II TV system lie in rapid data acquisition and instant display of the images. ${ }^{1-5}$ Because of these advantages, the II TV system can be applied to various radio-

Table 3. Comparison of Image Quality of II TV Digital Systems With Screen-Film System (Lower GI Series)

\begin{tabular}{|c|c|c|c|c|c|c|}
\hline \multirow[b]{2}{*}{ Technique } & \multicolumn{5}{|c|}{ Scores } & \multirow[b]{2}{*}{ Average } \\
\hline & 1 & 2 & 3 & 4 & 5 & \\
\hline \multicolumn{7}{|l|}{ II TV (1,024 pixels) } \\
\hline Original $(n=78)$ & $0(0 \%)$ & $51(65.4 \%)$ & $25(32.0 \%)$ & $2(2.6 \%)$ & $0(0 \%)$ & $2.39 \pm 0.54$ \\
\hline Unsharp masking $(n=78)$ & $0\langle 0 \%\rangle$ & $38(48.7 \%)$ & $33(42.3 \%)$ & $7(9.0 \%)$ & $0(0 \%)$ & $2.60 \pm 0.65$ \\
\hline \multicolumn{7}{|l|}{ II TV $(2,048$ pixels $)$} \\
\hline Original $(n=87)$ & $0\langle 0 \%)$ & $36(41.4 \%)$ & $47(54.0 \%)$ & $4(4.6 \%)$ & $0(0 \%)$ & $2.63 \pm 0.57$ \\
\hline Unsharp masking $(\mathrm{n}=87)$ & $0(0 \%)$ & $16(18.4 \%)$ & $58(66.7 \%)$ & $13(14.9 \%)$ & $0(0 \%)$ & $2.97 \pm 0.58$ \\
\hline
\end{tabular}

Values are number of evaluations for each score. Reprinted with permission from Takahashi et al. ${ }^{10}$ 
Table 4. Diagnosis on CRT Display (upper GI) Image Quality Compared With Screen-Film System

\begin{tabular}{ccc}
\hline & \multicolumn{2}{c}{ Image Matrix Size } \\
\cline { 2 - 3 } Display/Laser Printer & 2,048 Pixels & 1,024 Pixels \\
\hline 2,048-pixel display & 3.13 & 2.48 \\
With zooming & 3.64 & \\
1,024-pixel display & 2.91 & 3.10 \\
Laser printer & 3.19 & 2.90 \\
\hline
\end{tabular}

graphic examinations, especially to examinations requiring fluoroscopic control. The II TV system is suited for the upper GI examination, barium enema of the colon and various contrast examinations.

One of the critical limitations of the II TV system is the low spatial resolution because of the limited number of pixel. However, when a larger matrix size or smaller mode of image intensifier was used for imaging, the diagnostic quality and spatial resolution were almost equivalent to those of the screen-film system..$^{1-4}$

The basic properties and image quality of the II TV system with a 2,048- $\times 2,048$-pixel matrix were equivalent to those of the screen-film system. Minimal improvement in modulation transfer function of the system and in image quality of GI examinations were accomplished by upgrading the system, using a smaller $0.3-\mathrm{mm}$ focus.

In this study, the quality of CRT diagnosis of the upper GI tract using a high-resolution monitor was equivalent to that using a screenfilm system. This result shows the possibility of filmless diagnosis of GI tract using our II TV
Table 5. Diagnosis on CRT Display (upper Gl) Multi-Image Display

\begin{tabular}{clcc}
\hline & & \multicolumn{2}{c}{ Image Matrix Size } \\
\cline { 4 - 4 } Display & Diagnosis & 2,048 Pixels & 1,024 Pixels \\
\hline 2,048-pixel display & Easy & $39(75 \%)$ & $30(57 \%)$ \\
& Possible & $11(21 \%)$ & $18(35 \%)$ \\
& Impossible & $2(4 \%)$ & $4(8 \%)$ \\
1,024 -pixel display & Easy & $40(77 \%)$ & $32(61 \%)$ \\
& Possible & $10(19 \%)$ & $17(33 \%)$ \\
& Impossible & $2(4 \%)$ & $3(6 \%)$ \\
\hline
\end{tabular}

digital radiography system. The cost of x-ray film for GI examination is approximately $\$ 1.75$ / image. Using the recent introduced write-once $\mathrm{CD}-\mathrm{ROM}$, the cost of digital image storage is about 5 cents $/ 1$ Mbyte $(2,048 \times 2,048$ pixels, 8 bit image costs 20 cents), and the capacity is 650 Mbyte (about 150 images)/CD-ROM disc. The cost of digital image storage is now lower than that of the screen-film system and the storage space is also smaller.

In conclusion, II TV digital system has various advantages over the screen-film system for GI tract examination, when a 2,048-pixel matrix II TV is used. Upgrading the system to reduce the thickness of the photo-conductive layer and use of smaller focal spot improved the basic imaging property and clinical image quality. The possibility of CRT diagnosis, lower image storage cost, and smaller storage space will make the II TV digital radiography system an important method of digital radiography that will have compatibility with picture archiving and communication systems (PACS) in the future.

\section{REFERENCES}

1. Feczko PJ, Ackerman LV, Kastan DJ, et al: Digital radiography for the gastrointestinal tract. Gastrointest Radiol 13:191-196, 1988

2. Steiner E, Meuller PR, Hahn PF, et al: Digital video-fluorography for direct digital spot filming of gastrointestinal studies. Gastrointest Radiol 14:193-201, 1989

3. Edmonds EW, Rowland JA, Hynes DM, et al: Clinical experiences with a high-resolution digital imaging system for gastro-intestinal radiology. Proc SPIE 767:217-224, 1987

4. Takahashi $M$, Ueno $S$, Tsuchigame $T$, et al: Development of a 2,048 $\times$ 2,048-pixel image intensifier-TV digital radiography system: Basic imaging properties and clinical application. Invest Radiol 27:898-907, 1992

5. Takahashi M, Fukui K, Ueno S, et al: High resolution DSA: Experimental and clinical evaluation. Comput Radiol 10:213-219, 1986
6. Fujita $\mathrm{H}$, Doi $\mathrm{K}$, MacMahon $\mathrm{H}$, et al: Basic imaging properties of a large image intensifier-TV digital chest radiographic system. Invest Radiol 22:328-335, 1987

7. Takahashi $M$, Tsuchigame $T$, Ueno $S$, et al: Basic and clinical application of a 2,048 $\times 2,048$ image intensifier TV digital radiography system. Presented at the 76th Scientific Assembly and Annual Meeting of the Radiological Society of North America, Chicago, November 25-30, 1990

8. Takahashi M, Ueno S, Tsuchigame $\mathrm{T}$, et al: Improvement of physical imaging property of a $2,048 \times 2,048$ matrix image intensifier-TV digital radiography system. Presented at the 77th Annual Meeting of the Radiological Society of North America, Chicago, December 1-6, 1991

9. Takahashi M, Ueno S, Tsuchigame T, et al: A 2,048 $\times$ 2,048 matrix image intensifier-TV digital radiography system for gastrointestinal examinations. Presented at the 77 th 
Scientific Assembly and Annual Meeting of the Radiological Society of North America, Chicago, December 1-6, 1991

10. Takahashi M, Ueno S, Yoshimatsu S, et al: Gastrointestinal examinations with digital radiography. RadioGraphics 12:969-978, 1992

11. Sorenson JA, Niklason LT, Nelson A: Photographic unsharp masking in chest radiography. Invest Radiol 16:281288,1981

12. Loo LN, Doi K, Metz CE: Investigation of basic imaging properties in digital radiography. IV. Effect of unsharp masking on the detectability of simple patterns. Med Phys 12:209-214, 1985 